
\title{
S Research Square \\ SCAPP: An algorithm for improved plasmid assembly in metagenomes
}

David Pellow

Alvah Zorea

Maraike Probst

Ori Furma

Arik Segal

Itzhak Mizrahi

Ron Shamir

\section{Video Byte}

Keywords: plasmids, assembly, SCAPP, algorithm, metagenome, metagenomic sequencing, bacterial genome, DNA, horizontal gene transfer, antibiotic resistance, metagenomic samples, Sequence ContentsAware Plasmid Peeler, gut microbiome, plasmidome, Python, open source, Microbiome

Posted Date: October 14th, 2021

DOI: https://doi.org/10.21203/rs.3.rs-968130/v1

License: (c) (1) This work is licensed under a Creative Commons Attribution 4.0 International License. Read Full License 


\section{Abstract}

Advances in metagenomic sequencing have allowed for the identification of countless novel bacterial taxa in environmental samples. However, due to a lack of appropriate computational tools, the plasmids contained by many of these bacteria have received far less attention. That has restricted research into the important genetic processes plasmids are responsible for, such as horizontal gene transfer and antibiotic resistance. To address this gap, researchers recently developed the Sequence Contents-Aware Plasmid Peeler (SCAPP). An open-source Python package, SCAPP builds upon a previously developed algorithm and uses biological data to assemble plasmid sequences from metagenomic samples. SCAPP was found to outperform existing metagenomic plasmid assembly tools when tested on simulated metagenomes and real human gut microbiome samples. SCAPP could also assemble novel and clinically relevant plasmid sequences in generated samples. These findings indicate that SCAPP more effectively assembles plasmid sequences from large metagenomic datasets than previously developed methods and can potentially greatly enhance the current understanding of plasmid biology and microbial adaptation. 